\title{
Intellectual Capital In Mexican SMEs From The Perspective Of The Resource-Based And Dynamic Capabilities Views
}

Alain Daou, Laval University, Canada

Egide Karuranga, Laval University, Canada

Zhan Su, Laval University, Canada

\begin{abstract}
This paper combines the resource-based and dynamic capabilities views to examine intellectual capital in Mexican small and medium enterprises (SMEs) and its relation to competitive advantage. Following an exploratory approach, this paper relies on face-to-face interviews with managers to take an in-depth look at the three components of intellectual capital: human, organizational, and relational capital. Further, a SME typology is proposed and the examined companies are categorized accordingly. Dynamic SMEs have instituted internal and external processes to respond rapidly to change, allowing them to sense opportunities and threats and subsequently benefiting from competitive advantages. This analysis can help both managers and policymakers put appropriate programs in place to encourage SME development and growth by identifying the impact of intellectual capital. The generalizability of the results is limited by the small sample size and the focus on one geographic region in Mexico. This study contributes to the limited literature on intellectual capital in SMEs in emerging markets. Moreover, very few papers have analyzed intellectual capital from the perspective of the dynamic capabilities view.
\end{abstract}

Keywords: Intellectual Capital; Dynamic Capabilities View; Resource-Based View; SME, Emerging Markets; Mexico

\section{INTRODUCTION}

C ntellectual capital (IC), often defined in terms of human, organizational, and relational capital, has become a key determinant of the success of small businesses, especially during transitions from traditional factors of production to a knowledge-based economy (Piperopoulos, 2010). According to some authors, the competitive advantages and performance of small and medium enterprises (SMEs) are largely influenced by their intellectual capital (Cabello \& Kekäle, 2008; Cohen \& Kaimenakis, 2007; Jardón \& Martos, 2009; Lopez, 2006). In fact, intellectual capital is one of the main assets of businesses that support competitive advantages and are also the basis for value creation (Edvinsson \& Malone, 1997).

It has been demonstrated that IC generally has a positive impact on firm performance. However, its impact on SME performance in emerging economies is even stronger because for these companies, access to financial capital is limited. In addition, the role of these types of companies is crucial for local development (Jardón \& Martos, 2009; Piperopoulos, 2010). For instance, in Mexico, one of the major emerging countries, the last census conducted by the National Institute of Statistics and Geography (INEGI) in 2009 stipulated that SMEs represent $98.4 \%$ of all firms and support $78.5 \%$ of employment at the national level. Due to the small size and client proximity of SMEs, they have the ability to respond quickly to changes and adapt by managing the different opportunities or challenges they may encounter. With regard to innovation, it has been proven that SMEs generate more innovations per unit of financial capital than larger firms (OECD, 2010). Flexibility also allows these firms to adapt to niche markets and outperform large firms in terms of research and development (R\&D) (Bhagavatula, Elfring, van Tilburg, \& van de Bunt, 2010; Çakar \& Ertürk, 2010). 
However, although SMEs play a critical role, they also face major challenges, especially in emerging economies. They can hardly compete with large enterprises in attracting the highly skilled personnel necessary for innovation. It is difficult for them to engage in sufficient communication with other companies, foreign markets, and government agencies. They lack the capital to meet increasing demand and face challenges in registering patents. Furthermore, SMEs in emerging economies have a limited ability to make their voices heard when negotiating about and devising government policies (OECD, 2004). Above all, SMEs in emerging and developing countries are facing problems related to poor quality of human capital and the lack of required institutional capacities; they are therefore experiencing a deficiency in intellectual capital.

Given that there is a lack of understanding of the impact of intellectual capital on SMEs in emerging countries (Khalique, 2011; Phusavat, Comepa, Sitko-Lutek, \& Ooi, 2011), this research attempts to fill the existing literature gap on this evolving matter. More specifically, this research has two objectives: (1) to study the impact of intellectual capital on SMEs in an emerging country, i.e., Mexico, where resources and dynamic capabilities are either scarce or used differently from what is observed in most developed countries; and (2) to develop a new theoretical framework on intellectual capital that combines the resource-based view (RBV) and the dynamic capabilities view (DCV) by examining SMEs in the region of Queretaro, Mexico. To date, intellectual capital has been studied mostly from the perspective of the resource-based view, in which firms seek to take advantage of valuable, rare, inimitable, and non-substitutable resources. However, obtaining such resources is not sufficient. SMEs must also have the ability and structure to process their resources and transform them in a way that will allow them to attain a sustainable competitive advantage. This is especially true in highly dynamic environments and sectors (Wang \& Ahmed, 2007). Hence, we believe that the dynamic capabilities view is appropriate for the analysis of the intellectual capital of SMEs.

To achieve the objectives mentioned above, this paper is organized as follows. Section 2 is devoted to a literature review on the relationship between intellectual capital, the resource-based view, the dynamic capabilities view, and competitive advantage. Section 3 describes the research design and section 4 discusses the findings. Finally, we present the conclusion, contributions, and limitations of this study in section 5.

\section{LITERATURE REVIEW}

\subsection{Intellectual Capital}

Although there are many definitions of intellectual capital (Kaufmann \& Schneider, 2004), there is a consensus that IC creates value and supports the creation of competitive advantages in organizations. According to Edvinsson and Malone (1997), IC is defined as the possession of knowledge, organizational competence, technology, experience, customer relations, and professional skills that confer a competitive edge to their owner. Hence, IC is the combination of knowledge-bearing intellect, which, if well-managed by the firm, provides a sustainable competitive advantage (Cohen \& Kaimenakis, 2007). Consequently, intellectual capital is the sum of all the assets and capabilities that are not recognized and disclosed on the balance sheet but significantly contribute to the delivery of the organizational strategy.

Despite the lack of unanimity on the components of IC, consensus is growing as the field matures (Bontis, Keow, \& Richardson, 2000). One of the concepts upon which scholars do not agree relates to taxonomies and categorization of resources such as customer capital versus relational capital and organizational versus structural capital (Pike, boldt-Christmas, \& Roos, 2006). For instance, Cohen and Kaimenakis (2007) classified IC into human, organizational, and customer capital, whereby customer capital constitutes the most important component of relationships with stakeholders. Other authors have chosen to use five sub-domains (human, organizational, technological, business relations, and context) to classify firm intellectual capital (Rodriguez A., Rubio A., \& Esteban A., 2005). In a recent review of the literature on intangibles by El-Tawy and Tollington (2012), the authors provided different classifications and distinctions between internal and external structures and between business and social capital. In this study, we employed a broad definition of IC that is widely used by researchers and includes human, organizational, and relational capital (Choong, 2008; Gallego \& Rodriguez, 2005; Steenkamp \& Kashyap, 2010). 
Human capital can be defined as the knowledge, skills, and abilities of employees (Bhartesh \& Bandyopadhyay, 2005; Edvinsson \& Malone, 1997). It can be seen as the set of values, attitudes, and aptitudes of employees that leads to a competitive advantage and creates value for the organization (Jardón \& Martos, 2009). The importance of human capital cannot be overemphasized because it has been proven to be the most important aspect of IC (Boekestein, 2006; Choudhury, 2010; Cohen \& Kaimenakis, 2007; Durst, 2008; Jardón \& Martos, 2009). SMEs rely heavily on this resource and value human capital over other types of capital because it has a direct impact on SME productivity. Compared to large firms, the size of SMEs can be advantageous in terms of human capital because it allows for more interactions, promotes a friendly atmosphere, and encourages creativity and cooperation among employees (Ngah, 2009).

Organizational capital, also referred to as structural capital (Jardón \& Martos, 2009; Kamukama, Ahiauzu, \& Ntayi, 2010), is what remains in the SME when employees are not considered. It includes the core values of an SME, which are translated into the strategies and structure of the organization and lead to the diffusion of knowledge that can eventually be perceived as enhanced efficiency and performance (Cohen \& Kaimenakis, 2007). Organizational capital can be regarded as the internal structure of the organization. It includes patents, structures, policies, organizational culture, processes, and technology. This internal structure is built to support the firm's human capital (Clarke, Seng, \& Whiting, 2011; Yi \& Davey, 2010). According to a study on IC in Malaysia (Ngah, 2009), SMEs tend to keep good records of the practices they employ. Moreover, the culture of an SME facilitates cooperation among employees, supports creativity, and, along with the use of technology, encourages innovative practices.

Relational capital represents the external environment of the firm. It is the set of relationships (Jardón \& Martos, 2009) established with customers, suppliers, governments, and other stakeholders (Cohen \& Kaimenakis, 2007). Some researchers emphasize the role of customers and the SME-client relationship by including elements such as reputation and brand image in this dimension (Cohen \& Kaimenakis, 2007; Evans, Novicevic, \& Davis, 2007; Jardón \& Martos, 2009; Kiong T. \& Hooi H., 2009), while others focus on the role of the authorities and the policies that encourage or hinder SME development (Hamdam \& Damirchi, 2011; Huggins \& Weir, 2007a).

Even if the general characteristics and sub-domains of IC are generic (Cohen \& Kaimenakis, 2007) and applicable to all types of firms, SMEs, especially in developing economies, have particularities that are worth contemplating. As previously mentioned, given their small size, SMEs are flexible, have flat management structures, can respond quickly, and have a close relationship with their clients and suppliers. However, they also suffer from poor human capital, limited budgets, limited access to credit, and limited influence on governmental policies compared to bigger firms. Another key difference is their tendency to focus on human capital in their early stages instead of reinforcing organizational capital. This is due to the lack of financial resources and the time-consuming nature of implementing such processes and procedures (Durst, 2008; Huggins \& Weir, 2007b).

\section{$2.2 \quad$ Resource-Based View}

At the core of IC, the resource-based view has been a dominant theory. When developing competitive advantages from the perspective of the resource-based view, SMEs look for valuable, rare, inimitable, and nonsubstitutable (VRIN) resources. These resources can be regarded as the invisible assets that form IC (Kamukama, Ahiauzu, \& Ntayi, 2011). In order to comprehend the competitive advantages of SMEs, it is essential to understand resources. Barney (1991) concludes that "the resource-based view suggests that firms obtain sustained competitive advantages by implementing strategies that exploit their internal strengths, through responding to environmental opportunities, while neutralizing external threats and avoiding internal weaknesses". By resources, the author is referring to assets, capabilities, organizational processes, firm attributes, information, and knowledge, among others. Hence, resources can be categorized into three groups: physical, human, and organizational capital (Barney, 1991). While considering the implementation of the RBV in transitional and emerging economies, several studies have shown that human capital (education and training), organizational resources, and relational capital, such as reputation, influence firm growth and positively impact firm performance (Inmyxai \& Takahashi, 2009; Rangone, 1999).

Nevertheless, the RBV has its limitations. Some studies have demonstrated that in light of the resourcebased theory, intangibles could lock firms into a persistent disadvantage (Pal \& Soriya, 2012). To further ascertain 
this point of view, the example of R\&D is used to depict causal ambiguity, whereas investing in IC is seen as gambling with organizational resources (Dumay, 2009). Such a top-down approach has been criticized because there is no framework depicting the IC phenomenon; thus, other organizational theories offer explanations for IC in SMEs (Dumay, 2009; Kaufmann \& Schneider, 2004). According to Delery (1998), "while the resource-based view provides a nice backdrop explaining the importance of human resources to firms' competiveness, it does not deal with how [an] organization can develop and support the human resources it needs for achieving [a] competitive advantage". Therefore, the shift from the traditional competitive environment into today's fast-changing markets requires a more dynamic strategic alternative to the competitive advantage point of view (Stam, 2005).

\subsection{Integrating the Dynamic Capabilities View}

According to Teece et al. (1997), in a dynamic environment, a firm's competitive advantage depends on its ability to integrate, build, and reconfigure internal and external competencies to respond rapidly to competitive environments. In line with this, the dynamic capabilities view can better explain how and why some firms have a competitive advantage in this situation. Eisenhardt and Martin (2000) stressed that "dynamic capabilities are the organizational and strategic routines by which firms achieve new resource configurations as markets emerge, collide, split, evolve, and die."

Both the resource-based and dynamic capabilities views come from the field of economics (Mahoney, 2005), and we believe that the incorporation of latter can improve our understanding of the factors that affect SMEs. Thus, by combining the RBV and DCV in the context of our study, we can obtain a better grasp of IC and its impact on Mexican SMEs. The RBV is static in nature, making it insensitive to environmental changes (Teece, 2007; Teece, et al., 1997; Zaidi \& Siti Norezam, 2011). In contrast, the DCV is dynamic, and can better respond to environmental changes stemming from external volatility. This perspective is more comprehensive in explaining IC because external capital is one of its key components.

\subsection{Competitive Advantage through IC}

One of the main objectives of SMEs is to gain a sustainable competitive advantage that can be translated into growth and superior financial performance (Cheng, Lin, Hsiao, \& Lin, 2010). In order to accomplish this, there are four possible generic strategies that SMEs can choose from: gaining a sustainable cost advantage, differentiation from competitors, using a focus strategy, or using a differentiation focus strategy. By not having a clear strategy, firms tend to get stuck in the middle and possess no competitive advantages (Porter, 2008). From the RBV perspective, a competitive advantage is generated when a firm implements strategies that cannot be imitated by competitors or new entrants and hence becomes irreplaceable. Some potential approaches for SMEs would be to create value for their customers, use innovation as a strategy to outperform competitors, and implement an operational strategy to constantly improve internal activities. However, from the DCV perspective, in a dynamic marketplace, an SME's competitive advantage diminishes if it is not constantly renewed (Huang \& Kung, 2011).

Several authors link one or several components of IC to gaining a sustainable competitive advantage (Bogner, Thomas, \& McGee, 1999; Cheng, et al., 2010; Evans, et al., 2007; Huang \& Kung, 2011; Jardón \& Martos, 2009; Kamukama, et al., 2010, 2011). In today's globalized and constantly changing environment, IC is increasingly replacing tangible resources as the main source of the competitive advantages of firms (Cheng, et al., 2010; Kamukama, et al., 2011). However, depending on several internal and external factors, the different sub-domains of IC are not equally important as a source of competitive advantage (Kamukama, et al., 2010). Some studies confirm that human capital is at the heart of sustainable competitive advantages, whereby investing in the development of talent is the key to achieving a firm's strategic goals (Choudhury, 2010). Moreover, in a dynamic environment, it is by improving the competencies of employees and management that firms can improve management efficiency, subsequently leading to the acquisition and maintenance of a competitive position (Bogner, et al., 1999). Others find that internal practices, such as innovative capacity, and relational capital, such as customer base, are sources of sustainable competitive advantages for firms (Cheng, et al., 2010). Therefore, we posit that all aspects of IC are, to some extent, important factors for SMEs in Mexico to establish sustainable competitive advantages. 
Table 1: Comparing Intellectual Capital through the Resource-Based and Dynamic Capabilities Views

\begin{tabular}{|c|c|c|}
\hline & Intellectual Capital Through & Sustainable Competitive Advantage Through \\
\hline $\begin{array}{l}\text { Dynamic } \\
\text { Environment }\end{array}$ & $\begin{array}{l}\text { - Accumulation of experience and organizational } \\
\text { learning } \\
\text { - Development of dynamic capabilities and routines } \\
\text { - Innovative strategies } \\
\text { - Dynamic responses to environmental changes }\end{array}$ & $\begin{array}{l}\text { - Changing routines and resource bases } \\
\text { - Ability to sense, react to, and manage threats } \\
\text { - Ability to transform and adapt to threats and } \\
\text { opportunities } \\
\text { - Collective activity systematically generating } \\
\text { improved effectiveness }\end{array}$ \\
\hline $\begin{array}{l}\text { Static } \\
\text { Environment }\end{array}$ & $\begin{array}{l}\text { - Employee motivation and competencies } \\
\text { - Resources such as patents and technology } \\
\text { - Established relationships with customers, suppliers, } \\
\text { governments, and other stakeholders }\end{array}$ & $\begin{array}{l}\text { - Valuable, rare, inimitable, and non-substitutable } \\
\text { resources } \\
\text { - Strategies making the firm irreplaceable } \\
\text { - Creating routines and acquiring resources }\end{array}$ \\
\hline
\end{tabular}

\section{RESEARCH DESIGN}

\subsection{Research Propositions}

In terms of human capital, the dynamic capabilities and resource-based views are complementary to each other. Two aspects are considered when discussing human capital: the perspectives of the manager/owner and employees. From the managerial point of view, education and experience are taken into consideration (McKelvie \& Davidsson, 2009). This approach goes hand-in-hand with the definition of human capital from the IC perspective (Edvinsson \& Malone, 1997; Jardón \& Martos, 2009). The human capital of employees is regarded as comprising their skills and capabilities. It includes elements such as training, knowledge, and motivation (Edvinsson \& Malone, 1997; McKelvie \& Davidsson, 2009). Consequently, we propose that:

P1: Human capital has a significant influence on the competitive advantages of SMEs.

Firms with strong dynamic capabilities are highly entrepreneurial. This characteristic is imperative for the survival of SMEs in developing economies given their limited access to financing and support from the authorities (Ruiz, 2001). Capabilities can be perceived as the capacity to determine opportunities and threats, seize opportunities, and continually maintain, protect, and enhance competitiveness in order to sustain a competitive advantage. In today's globalized markets, SME managers in developing economies must detect new opportunities by either accessing external information or creating new knowledge (Teece, et al., 1997). This type of detection can be driven internally (by building commitment, training employees, and implementing organizational processes that encourage innovation) or externally (by knowing customer needs and building strong relationships with suppliers and other stakeholders). Once an opportunity is recognized, its exploitation involves investing in development and commercialization. Such a decision demands skills and judgment on the part of managers, whereby taking such an action can be risky for an SME. Finally, transformation is related to adapting and reconfiguring when changes occur.

P2: Organizational capital has a significant influence on the competitive advantages of SMEs.

Truijens (2003) compares the RBV to a strengths, weaknesses, opportunities, and threats (SWOT) framework that did not take opportunities and threats stemming from the external environment into account. To fill this gap, the DCV looks at the influence of the external environment on the firm. From the IC perspective, external capital is one of the three key components. It reflects established relationships with third parties such as customers, suppliers, governments, and competitors (Cohen \& Kaimenakis, 2007; Jardón \& Martos, 2009). SME managers must constantly consider external changes, including government legislation, new competitors, and customer needs (Bowman \& Collier, 2009), which are constantly evolving. Moreover, the dynamic interactions among the different factors influencing managers allows for the better adaptability of the DCV in different cultural settings, such as our research on SMEs in Mexico.

P3: Relational capital has a significant influence on the competitive advantages of SMEs.

By emphasizing the importance of non-traditional sources of competitive advantage (Barreto, 2009; Mahoney, 2005) such as managerial capabilities, human resources, intellectual capabilities, and network of relationships, among others, the DCV reflects the importance of intellectual capital in SMEs while also providing 
the tools to observe such resources (Truijens, 2003). The intellectual resources from a dynamic capabilities perspective are unattainable with money alone; time-consuming to develop; can have multiple, simultaneous uses; and are able to yield multiple, simultaneous benefits (Mahoney, 2005).

P4: Dynamic capabilities have a significant influence on the competitive advantages of SMEs.

By combining our hypotheses, we generate a typology of SMEs (see Figure 1). Our first category, called sclerotic, includes SMEs that have low intellectual capital and low dynamic capabilities. These are most likely to disappear in the short term if corrective measures are not taken. The second group includes wannabes. A wannabe SME has low intellectual capital and high dynamic capabilities. Such firms are likely to have a short-term focus and are able to respond dynamically to environmental changes but have not instituted routines and do not have a longterm strategy. Reactive SMEs are characterized by high intellectual capital but low dynamic capabilities. Such firms are likely to have strong routines and procedures. However, they are self-centered and therefore do not evaluate opportunities and threats in a timely manner. Finally, chameleon SMEs score high on intellectual capital and dynamic capabilities. These firms have competent human capital, routines and procedures, and score high on relational capital. Moreover, such firms can adapt their routines because they have the ability to sense and react to opportunities and threats in order to improve effectiveness.

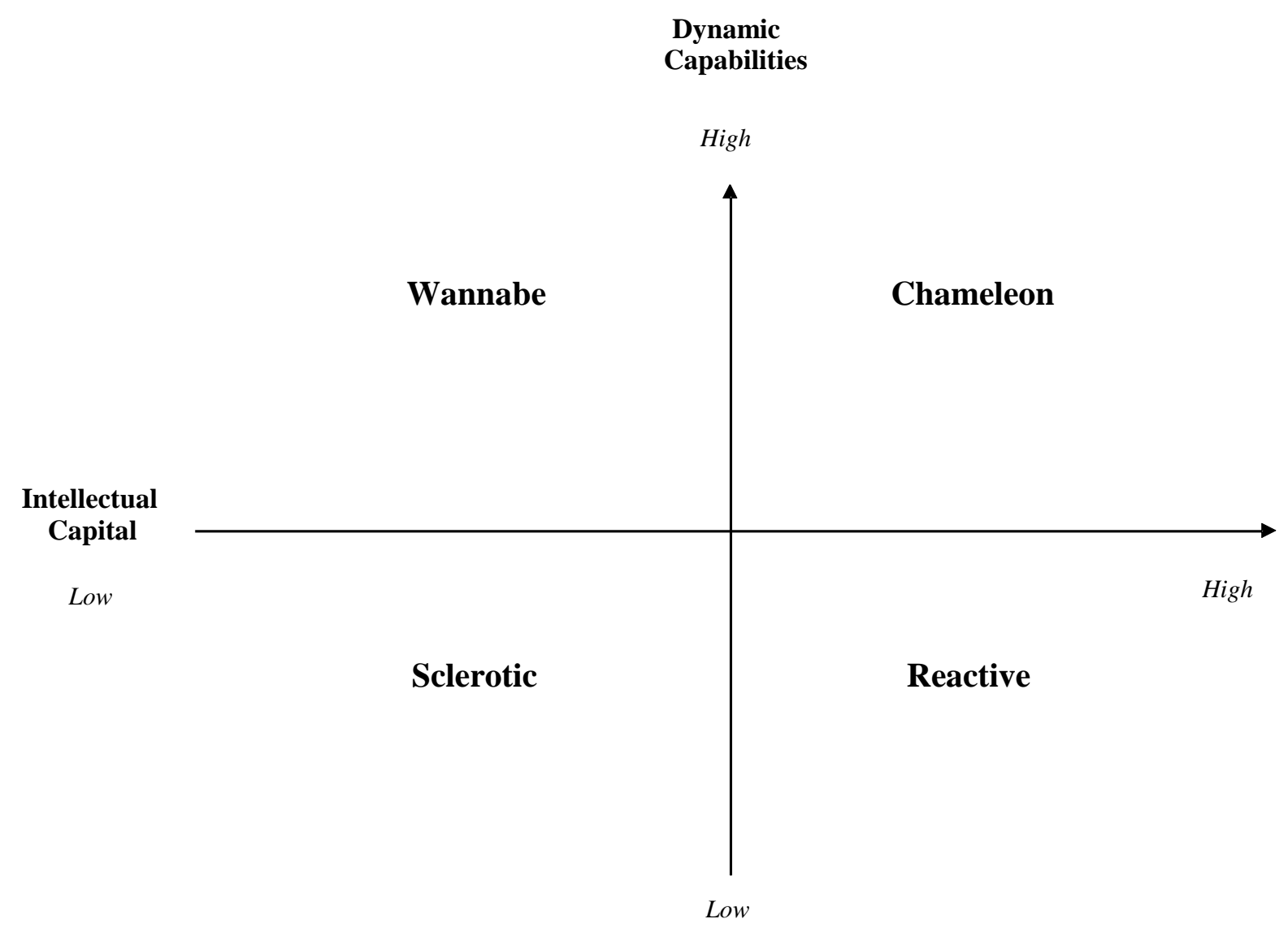

Figure 1: SME Typology

\subsection{Methodology}

The objective of this study is to combine the RBV and DCV to understand the impact of IC of SMEs in Mexico. In our research, we used the definition of SMEs used in Mexico, which was updated in 2009 (INEGI, 2009) and incorporates sector type, number of employees, and sales volume. 
Table 2: Definition of SMEs in Mexico as of 2009

\begin{tabular}{lcccc}
\hline \multicolumn{1}{c}{ Size } & Sector & Employees & Sales Volume & Maximum Combined* \\
\hline Micro & All & 10 or less & $\$ 4$ or less & 4.06 \\
\hline \multirow{2}{*}{ Small } & Commerce & 11 to 30 & $\$ 4.01$ to 100 & 93 \\
& Industry \& services & 11 to 50 & $\$ 4.01$ to 100 & 95 \\
\hline \multirow{2}{*}{ Medium } & Commerce & 31 to 100 & $\$ 100.01$ to 250 & 235 \\
& Services & 51 to 100 & $\$ 100.01$ to 250 & 250 \\
\hline
\end{tabular}

* Maximum combined $=($ workers $)$ X 10\% + (annual sales $)$ X 90\%

Following a qualitative approach, which facilitates the comprehension of the context and permits an indepth analysis, we interviewed managers and owners of Mexican SMEs from different economic sectors (Maxwell, 2005). The perspectives of the owners and managers of SMEs were collected to analyze their views with respect to the challenges they face in developing intellectual capital in their organizations. A total of 24 face-to-face interviews were conducted to collect opinions. This strategy was adopted because interviews are best performed in the form of an in-person conversation rather than over the telephone (Kvale, 1996; Maxwell, 2005).

This study is based on semi-structured interviews conducted in the area of Queretaro in Mexico between January and May of 2012. Interviews lasted an average of one hour and were completely transcribed (Palys \& Atchison, 2008). Respondent confidentiality was guaranteed. Table 3 presents the relevant information on the sample of interviewees. The main topics that were addressed included general information about the interviewee, general information about the SME, and information on the human, organizational, and relational capital components of IC. In addition, the views of managers were surveyed to understand the financial and non-financial impacts of IC on organizational performance.

Table 3: SME Interviewee Information

\begin{tabular}{|c|c|c|c|c|}
\hline Case & Sector & Established & Position & Market \\
\hline 1 & IT/consulting & 2010 & Owner/director & Regional \\
\hline 2 & HR management & 2010 & Owner/director & Regional \\
\hline 3 & IT/software development & 2010 & Director & International \\
\hline 4 & IT/software development & 2008 & Owner/director & National \\
\hline 5 & Construction & 2008 & Owner/director & National \\
\hline 6 & IT/software development & 2006 & Owner/director & International \\
\hline 7 & Furniture/design & 2009 & Owner/director & National \\
\hline 8 & Industrial engineering & 2006 & Director & Regional \\
\hline 9 & Renewable energy & 2010 & Owner/director & National \\
\hline 10 & Manufacturing & 2009 & Owner/director & National \\
\hline 11 & Furniture/design & 2011 & Owner/director & Regional \\
\hline 12 & IT/business consulting & 2011 & Owner/director & National \\
\hline 13 & IT/software development & 2010 & Owner/director & National \\
\hline 14 & IT/software development & 2005 & Owner/director & Regional \\
\hline 15 & IT/software development & 2011 & Administrator & National \\
\hline 16 & IT/consulting & 2006 & Director & Local \\
\hline 17 & Construction & 2010 & Owner/director & Regional \\
\hline 18 & IT/software development & 1997 & Owner/director & International \\
\hline 19 & Construction & 2004 & Owner/director & National \\
\hline 20 & IT/software development & 2006 & Area director & National \\
\hline 21 & Communication & 2008 & Owner/director & National \\
\hline 22 & Mechanical engineering & 1990 & Owner/director & International \\
\hline 23 & Mechanical engineering & 1999 & HR manager & International \\
\hline 24 & Training/education & 2010 & Owner/trainer & Regional \\
\hline
\end{tabular}

Data analysis was conducted by combining and comparing information from different sources including interviews, documents, and websites. This method allows for data triangulation (Maxwell, 2005). Systematic interview analysis was conducted by examining the common themes from our sample. After transcribing the interviews, QDA Miner (V4.0.4) software was used to codify and analyze the results. Finally, we conducted a content analysis of the results. 


\section{RESULTS AND DISCUSSION}

The results from the analysis of the interviews and documents allowed us to make some important observations regarding the development of intellectual capital among Mexican SMEs. The results are presented according to our research framework.

\subsection{Human Capital}

The findings show that human capital is often regarded as one of the main challenges facing SMEs in Mexico as they develop and grow. The managers we met revealed several challenges during the interviews and agreed that most of the human resources they hire lack skills. However, many stressed the importance of training and investing in the acquisition of skills. That being said, and given the scarce resources of SMEs, most training is informal and on the job.

Mainly it (training) is done externally; there is also some internal training, but it relies mostly on the sharing of experience. The training given internally is somewhat informal. (Case 14)

When considering the motivation of employees, the interviewed managers focus on three key points leading to employee satisfaction and retention within the organization: training and the possibility of gaining experience, salary and benefits, and the relationship between management and employees.

It's very important to motivate them (employees); there are several ways, but the most obvious is economic. We try to keep a healthy coexistence and avoid things that harm the relationship we have with employees. We try to keep them motivated, but it is a difficult process. HR is always a complex issue, but at least the ultimate goal is attained. (Case 13)

In terms of human resource management and accounting, several SMEs opted for outsourcing because they lack the capabilities to do it internally. However, this tendency to rely on outsourcing is mainly found among SMEs that are in the information and communication technologies (ICT) sector. SMEs in other sectors have the tendency to rely mostly on the owner/manager to perform multiple tasks. Moreover, two opposing views regarding human capital are expressed in the interviews. On the one hand, dynamic SMEs recognize the importance of investing, developing, and creating a work place that is conducive to the development of human capital and innovation.

Since we are in ICT, what we are building is not manpower but rather minds, and information technologies industry generally offers good wages. (Case 21)

On the other hand, SMEs with low dynamic capabilities tend to have less awareness of the importance of investing in employees because some feel that employees are in need of jobs and will not leave due to their economic situation.

No, we do not do any of that (retention plan) and I've never really evaluated it as something that might have some benefit or might be motivating for employees. I have no idea how or what to do and what impact it may have. (Case 19)

\subsection{Organizational Capital}

Dynamic capabilities can be regarded as the organizational and strategic routines that help firms achieve new resource configurations (Eisenhardt \& Martin, 2000). The routines implemented by SMEs are related to the organizational processes that help firms adapt to a changing environment.

The interviewed Mexican SMEs are aware of the importance of implementing procedures and systems within their organizations. Most SMEs said that they follow the national rules and regulations in terms of wages and benefits; however, they do not have any internal documents in relation to this. This lack of documentation is seen in all types of SMEs with low or high dynamic capabilities. While most SMEs recognize the importance of establishing internal procedures, they agree in saying that they lack the skills, resources, and time to do it, as well as 
that it is not a priority for them at this stage. Detailed job descriptions seem to be common to most SMEs because each position in the organization has a detailed profile. With regard to other administrative and financial aspects, guidelines, manuals, and databases are clearly lacking.

Yes, right now all the positions are well defined; employees already have a job profile and know that this profile matches the duties that must be performed to accomplish their tasks. All documentation is written, so that your employee knows how you evaluate him. (Case 13)

Planning is a key aspect of management routines. Only four interviewed SMEs (cases 3, 6, 18, and 22) confirmed engaging in annual planning involving all key staff. These SMEs have an international reach and are keen to have a positive image. Moreover, in order to increase their credibility for their international clients, they have established procedures and processes as a result of their ISO certifications.

Yes, the company has been ISO 9001 certified for over ten years now and part of the certification is to have an organizational chart with job descriptions, designated responsibilities, and all those issues; that is where we have everything scheduled. (Case 22)

On the other hand, SMEs that think and act locally tend to have informal management systems in place, whereby the internal structures are less defined. Hence, the policies and decision-making processes are centralized among high-level management.

We do plan, but it is not very formal, we have general objectives, some steps to follow, but it is not highly institutionalized, what we do is we establish overall objectives. (Case 14)

We also noted that access to information and hierarchies are highly knotted. It is well known that power distance is high in the Mexican context because it is a highly centralized, hierarchical society with clear inequalities between management and employees (Hofstede, 1984). However, our findings suggest that SMEs that operate in highly dynamic environments tend to have flatter structures, provide access to information at all levels of the organization, and encourage employees to participate in decision-making processes.

As a young company, we have an open space policy. We have different positions here, but our platform is very horizontal, the scheme of work is multidisciplinary; we encourage teamwork, working between departments, trying to motivate teams to work together, so we can say that in the end the job is done together. (Case 20)

In contrast to this point of view, low-dynamic-capacity SMEs (cases 5, 7, 9, 10, 11, 17, 19, and 23) tend to restrict access to information among lower-level employees and operate with a more defined hierarchy in which top management plans and makes decisions without consulting other employees. Hence, we recognize the presence of a large power distance in such organizations.

In addition to managerial processes, another fundamental issue is the management of intellectual property in general and patents in particular. All interviewed SMEs were aware of the importance of protecting their processes and products. However, very few have done so, or even begun to attempt it, for a number of stated reasons. Among these, the most commonly mentioned include lack of resources, lack of know-how, lack of required financial resources, lack of trust in the patenting process in Mexico, and fear that others will steal their idea. On the other hand, SMEs seem to be keen on buying international licenses and are proud to mention this because it presents a positive image of their organizations.

In terms of technological processes, the interviewed SMEs acknowledge their importance and invest heavily in information technologies. This observation can be generalized to SMEs in all sectors and is not restricted to one area in particular. Furthermore, SMEs regard technologies as representing an opportunity to reduce the gap between them and larger firms that have highly skilled human capital and access to financial resources. Technological processes are closely linked to innovation as a key to enabling organizations to develop a sustained competitive advantage. The interviewed managers agreed that information and communication technologies were the main factors allowing them to implement process innovations that contribute to improved internal communications, create management systems, and establish better monitoring systems for markets and competitors. 
We have a monitoring system for technologies and for the market where we see what is happening in our environment, new trends in products or services, and what world leaders are doing. We have access to databases that give us a good picture of what's going on and on that basis, we plan the entry or exit of products to our market. (...) We have continuous improvement objectives in all business processes, be it operation, administrative, marketing, technological, etc. In our operation, we can improve how we manage our HR, accounting, and procurement systems, which were all manual and are now computerized and directly connected to our wireless network. (Case 18)

\subsection{Relational Capital}

Relational capital refers to the external environment and its impact on SME performance. The image of the organization, customer satisfaction, and the relationship with stakeholders were cited as being important for SME development. During the interviews with managers, the role played by the government was prominent in the discussion; therefore, its role cannot be underestimated. In Mexico, there are 131 different programs aimed at promoting the productivity and competitiveness of SMEs. These programs, created mostly between 1995 and 2000, are managed by different governmental agencies (The World Bank, 2007). Most interviewed SMEs had a favorable view of such initiatives, and a considerable number had received assistance from those entities.

I benefited from México Emprende; it is an incubation process that is subsidized by the government, the Secretaria de Economia and PYME Fund. Such assistance had some benefits such as the creation of my website, and my brand was created with the help of México Emprende. Such benefits are good, and I do not undervaluethem, but the real benefits are financial, in cases when access is impossible. (Case 1)

As previously mentioned, despite many advances and implemented programs, access to financing is still an obstacle for Mexican SMEs. For instance, just $18 \%$ of SMEs in Mexico received loans from commercial banks (Lopez-Acevedo \& Tinajero-Bravo, 2010). Access to capital continues to be the main concern of the interviewed SMEs. This is why most start-ups and smaller SMEs rely heavily on personal financing or assistance from family. This is particularly true for firms operating in highly dynamic sectors such as ICT, a sector with greater risks and fewer assets than traditional sectors.

For businesses related to information technologies, access to credit is nearly impossible because banks and lending institutions focus on our assets to grant loans. The activity in this industry involves the person's mind, in contrast to other sectors. In the case of companies in information technologies, we have only computers and furniture; everything else is related to our minds, so there have been hardly any credit programs targeting us. (Case 16)

When considering the relationships of organizations with their external environment, customer satisfaction and the building of close relationships are viewed as the main competitive advantages by a large number of the interviewed SMEs. This is intrinsically linked with the image of the SME as well as competitiveness in the targeted markets. Managers view these relationships over the long-term, by building customer loyalty and thus improving their market positions. A particularity of the Mexican context is the relationship of SMEs with the community at large.

I think we have a positive image, because of the quality of the services that we have delivered. We have been recommended to other clients. This is something that we value; it is crucial. Alliances are borne from good relations, where we had new opportunities to sell new products and services that would not have been there without these relationships. It is crucial and essential since our customers are recommending us. (Case 4)

In IC, relational capital is often viewed in terms of clients, the local authorities, and suppliers. However, our findings are distinct due to the magnitude of the impact of SMEs in the community. Managers agree that the image of their organizations in the communities where they operate is important because they value making a positive impact and having close ties with different stakeholders. 


\subsection{Dynamic Capabilities}

Managers of Mexican SMEs need to integrate and coordinate capabilities to gain a sustainable competitive advantage. This task would need to be conducted both internally and externally, by dynamically integrating the three components of IC to ensure the creation of synergies and involving all stakeholders in the process. The interviewed managers agree on the importance of anticipating changes and responding to them; however, once again, the pace and priority given to this type of adaptation process differs between dynamic and less dynamic SMEs. Dynamic firms see internal knowledge accumulation as the sum of interactions with different stakeholders, which in turn, if exploited, can provide SMEs with a competitive advantage.

I believe that everyone creates their own opportunity. We do not sell systems; we see ourselves as a company that partners with its clients to achieve objectives through the development of software. We want it to be seen differently, to have a long-term relation where in addition to providing the service, we become an ally that enables our clients to be more competitive, having a lead pair. So I believe that competition has a little more to do with helping our partner to be competitive and to compete with each other to be better. (Case 14)

Moreover, this dynamic process must be ongoing, allowing the SME to respond to changes in its internal and external environments and constantly reinvent itself. For this to happen, firms need to implement a plan setting short- and long-term objectives to integrate new capabilities.

In planning for SMEs, you need to set a goal now knowing that over time it can be modified; that does not mean you let go of a goal but over time, objectives and priorities change. It can be changing in the sense that you reached the goal that you set, or that your priorities have changed. (Case 1)

Overall, our theoretical model and its propositions are confirmed. The interviews demonstrate that the combined RBV and DCV analysis leads to a greater competitive advantage. To further analyze the results, we plotted the interviewed SMEs according to our typology (Figure 2). On the horizontal axis, we considered the subcomponents of intellectual capital as being either low or high. As previously discussed, human, organizational, and relational capital form the intangible resources of the SMEs (Cohen \& Kaimenakis, 2007; Edvinsson \& Malone, 1997). In our sample, nine SMEs were identified as having low intellectual capital, while 16 were identified as high. In Mexico, most high-IC SMEs are characterized by a having top management that have high levels of education and/or experience on as well as appropriate organizational procedures such as certifications and intellectual property. It was found that organizations serving or planning to enter international markets tend to nurture local and international relationships while trying to implement formal processes and procedures. 


\section{Dynamic \\ Capabilities}

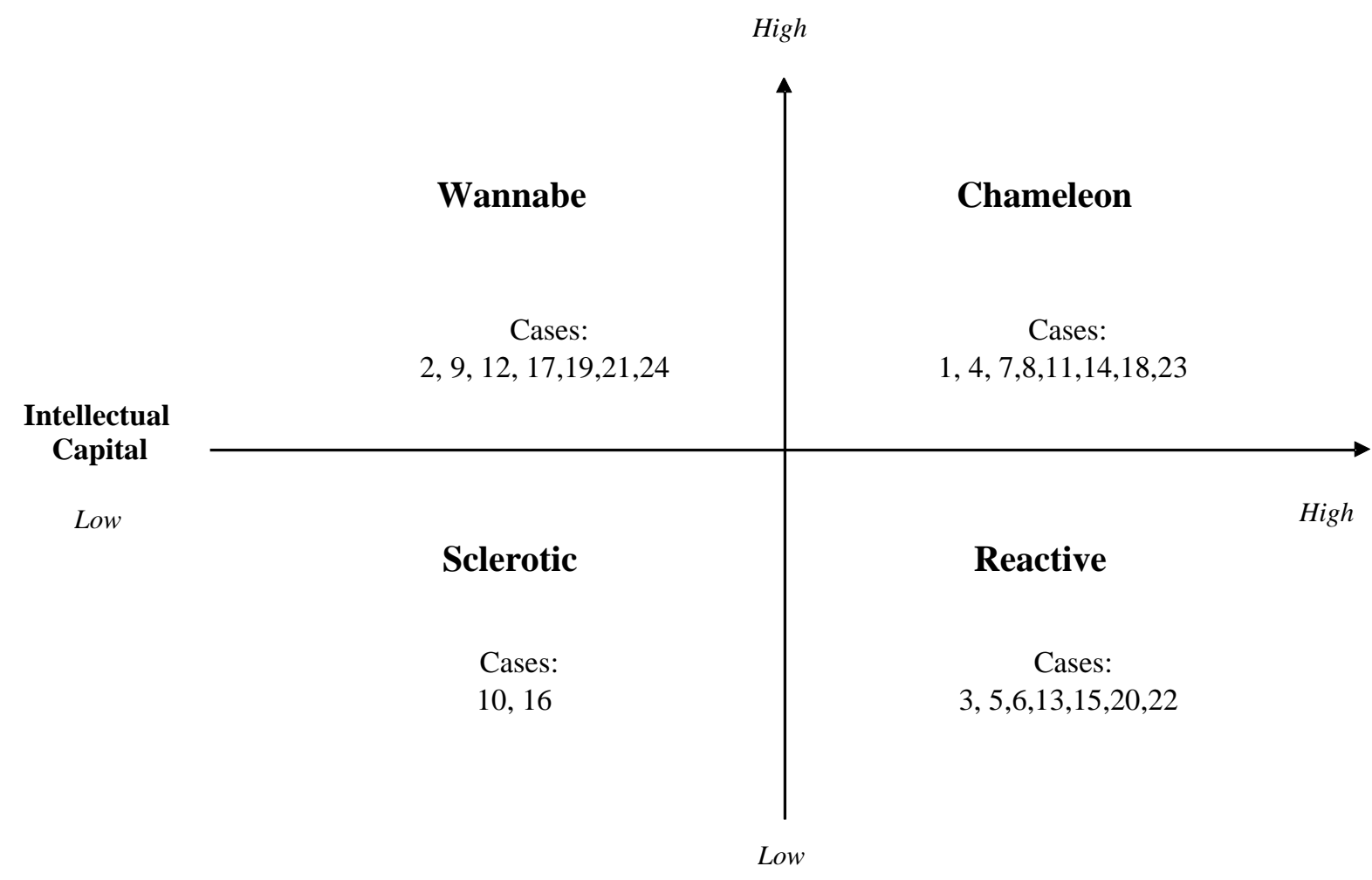

Figure 2: Examined SMEs According to Proposed Typology

On the vertical axis, SMEs are plotted according to their dynamic capabilities. Going beyond the RBV, firms need to implement internal and external strategic processes to manipulate their resources and create value (Eisenhardt \& Martin, 2000). Out of the 24 interviewed SMEs, we identified nine with high dynamic capabilities and 16 with low dynamic capabilities. Highly dynamic SMEs are found have established routines, high adaptability, a high capacity for learning, and the ability to create new knowledge for specific situations (Teece, 2007). Highly dynamic SMEs are aware that they operate in high-velocity markets, whereby SMEs in rapidly changing environments need to develop the capacity to constantly transform and adapt (Teece \& Pisano, 1994).

\section{CONCLUSION}

The objective of this study was to present intellectual capital through a new perspective combining the RBV and DCV. Within the context of SMEs in Mexico, IC is analyzed from the perspective of both the RBV and DCV. It was found that SMEs need to adapt in order to obtain and safeguard sustainable competitive advantages in an ever-changing environment. Following a qualitative approach, which facilitates the comprehension of the context and permits an in-depth analysis, we interviewed 24 managers and owners of Mexican SMEs from different economic sectors (Maxwell, 2005). This study contributes to the limited literature on IC in SMEs in emerging markets (Cohen \& Kaimenakis, 2007; Hamdam \& Damirchi, 2011; Khalique, 2011; Ngah, 2009; Phusavat, et al., 2011; Steenkamp \& Kashyap, 2010). Moreover, very few papers have analyzed IC from the DCV perspective (Hsu \& Wang, 2012).

The results suggest that SMEs with dynamic capabilities have instituted processes within their organizations to respond more rapidly to change, allowing them to manage opportunities and threats. Moreover, they are willing to take more risks than their counterparts, who are characterized by less dynamism in seizing opportunities and transforming them into competitive advantages. 
It is necessary for firms to have dynamic capabilities for long-term performance because SMEs need to respond to changes in the external environment, which can be culture- and industry-specific (Wang \& Ahmed, 2007). Such adaptation impacts the relational capital of firms because regulations put in place by the Mexican authorities, access to financing, customer capital, and relationships with different stakeholders have to be taken into consideration by managers in order to apprehend and respond to market opportunities by adapting and transforming. This impact, although it comes primarily from the external environment, affects human and organizational capital. Internal capital (human and organizational) allows SMEs to manage knowledge within the organization and plays a role in the potential exploitation of identified opportunities. As previously mentioned, in highly dynamic environments, SMEs need to have the adequate processes in place to be able to adapt and seize opportunities. Such processes are intrinsic to SMEs because they become part of the culture of organizations. Moreover, in such dynamic markets, the ability to respond quickly to threats and opportunities often determines the chances that small firms will survive. Accordingly, a horizontal organizational structure allows for better dissemination of information and quicker responses to changes.

Both scholars and practitioners can benefit from this research. The main contribution of this study is to open the door to a new theoretical perspective on intellectual capital and analyze it in combination with dynamic capabilities. At a practical level, this study is important to both managers and policymakers. SMEs should capitalize on IC by devoting appropriate resources to its development at the human, organizational, and relational levels. Given limited access to financial resources, the impact of IC is even greater in SMEs, giving them a clear competitive advantage. Policymakers should adapt their programs to the realities and needs of SMEs with regard to IC. The results provide the basis for further research on the subject, while questioning the current IC model and its limitations, as previously discussed.

Given the exploratory nature of this study, the results have some limitations. The small sample size, as well as the focus on one region (Queretaro) in Mexico does not allow us to generalize the results. However, beyond the local foci, there are some useful lessons for understanding the phenomenon as a whole. Further research could be conducted, for instance, to examine the link between IC and DCV in other markets by testing the proposed typology. Moreover, given the evolutionary process of the dynamic capabilities through which SMEs sense, seize, and transform opportunities, a longitudinal study could help deepen our understanding of the relationship between DCV and the elements of intellectual capital. Finally, quantitative surveys in Mexico could provide further knowledge on IC in emerging economies because these countries have received little research attention. Such an approach would validate our exploratory study on the relationship among intellectual capital, the resource-based view, and dynamic capabilities.

\section{ACKNOWLEDGEMENTS}

Authors would like to thank Louis Felipe Torres Gomez from the Instituto Tecnológico y de Estudios Superiores de Monterrey (Campus Queretaro) for his support and guidance.

\section{AUTHOR INFORMATION}

Alain Daou is a Ph.D. candidate in management at Laval University. He is a member of the Stephen A. Jarislowsky Chair in International Business Management. His research is dedicated to intellectual capital in emerging and developing countries. Alain DAOU, Ph.D. candidate in management at Laval University, Department of Management, Laval University, Pavillon Palasis-Prince, 2325, rue de la Terrasse suite 2457, G1V 0A6, Quebec, QC. Canada. E-mail: alain.daou@fsa.ulaval.ca (Corresponding author)

Dr. Egide Karuranga is currently Associate professor of International Business and Human Resource management at Faculty of Administrative Sciences, Laval University, Canada. He has numerous research papers published in leading peer reviewed journals and won several best paper awards. He has presented his research works in leading international conferences in Management and won "best paper award" at the AOM, ASAC, 2012 and AGBA, 2013 conferences. His current research interest falls on Cross-cultural Management, technology and development and Innovation in the emerging countries. Egide Karuranga, Ph.D., Department of Management, Laval University, Quebec, QC, Canada. E-mail: egide.karuranga@fsa.ulavel.ca 
Dr. Zhan Su is a professor of business strategy and international management at Laval University, Canada and director of the Stephen A. Jarislowsky Chair in International Business. He has already presented papers in more than eighty national and international conferences and received several prestigious awards for his research and teaching. S. U. Zhan, Ph.D., Department of Management, Laval University, Quebec, QC, Canada. E-mail: Zhan.Su@fsa.ulaval.ca

\section{REFERENCES}

1. Barney, J. (1991). Firm resources and sustained competitive advantage. Journal of Management, 17(1), 99120.

2. Barreto, I. (2009). Dynamic Capabilities: A Review of Past Research and an Agenda for the Future. Journal of Management, 36(1), 256-280. doi: 10.1177/0149206309350776.

3. Bhagavatula, S., Elfring, T., van Tilburg, A., \& van de Bunt, G. G. (2010). How social and human capital influence opportunity recognition and resource mobilization in India's handloom industry. Journal of Business Venturing, 25(3), 245-260.

4. Bhartesh, K. R., \& Bandyopadhyay, A. K. (2005). Intellectual Capital: Concept and its Measurement. Finance India, 19(4), 1365.

5. Boekestein, B. (2006). The relation Between Intellectual Capital and Intangible Assets of Pharmaceutical Companies. Journal of Intellectual Capital, 7(2), 241-253.

6. Bogner, W. C., Thomas, H., \& McGee, J. (1999). Competence and competitive advantage: towards a dynamic model. British Journal of Management, 10(4), 275-290.

7. Bontis, N., Keow, W., \& Richardson, S. (2000). Intellectual capital and the nature of business in Malaysian industries. Journal of Intellectual Capital, 1(1), 85-100.

8. Bowman, A., \& Collier, N. (2009). Dynamic capabilities: An exploration of how firms renew their resource base. British Journal of Management, 20(1), 9-24.

9. Cabello, C., \& Kekäle, T. (2008). Managing intellectual capital in small ITC companies. Business Strategy Series, 9(4), 163-167.

10. Çakar, N. D., \& Ertürk, A. (2010). Comparing Innovation Capability of Small and Medium Sized Enterprises: Examining the Effects of Organizational Culture and Empowerment. Journal of Small Business Management, 48(3), 325-359.

11. Cheng, M.-Y., Lin, J.-Y., Hsiao, T.-Y., \& Lin, T. W. (2010). Invested Resource, Competitive Intellectual Capital, and Corporate Performance. Journal of Intellectual Capital, 11(4), 433-450.

12. Choong, K. K. (2008). Intellectual capital: definitions, categorization and reporting models. Journal of Intellectual Capital, 9(4), 609-638.

13. Choudhury, J. (2010). Performance Impact of Intellectual Capital: A Study of Indian IT Sector. International Journal of Business and Management, 5(9), 72.

14. Clarke, M., Seng, D., \& Whiting, R. H. (2011). Intellectual capital and firm performance in Australia. Journal of Intellectual Capital, 12(4), 505-530. doi: http://dx.doi.org/10.1108/14691931111181706.

15. Cohen, S., \& Kaimenakis, N. (2007). Intellectual capital and corporate performance in knowledge-intensive SMEs. The Learning Organization, 14(3), 241-262. doi: http://dx.doi.org/10.1108/09696470710739417.

16. Delery, J. E. (1998). Issues of fit in strategic human resource management: Implications for research. Human Resource Management Review, 8(3), 289-309. doi: http://dx.doi.org/10.1016/S10534822(98)90006-7.

17. Dumay, J. (2009). Intellectual Capital Measurement: A Critical Approach. Journal of Intellectual Capital, 10(2), 190-210.

18. Durst, S. (2008). The relevance of intangible assets in German SMEs. Journal of Intellectual Capital, 9(3), 410-432.

19. Edvinsson, L., \& Malone, M. S. (1997). Intellectual Capital: Realizing your company's true value by finding its hidden brainpower. New York: Harper Business.

20. Eisenhardt, K. M., \& Martin, J. A. (2000). Dynamic capabilities: What are they? Strategic Management Journal, 21(10/11), 1105-1121.

21. El Tawy, N., \& Tollington, T. (2012). Intellectual Capital: Literature Review. Int. J. Learning and Intellectual Capital, 9(3), 241-259. 
22. Evans, W. R., Novicevic, M. M., \& Davis, W. D. (2007). Resource-Based Foundations of Strategic Human Resource Management: A Review and Extension. Int. J. Learning and Intellectual Capital, 4(1/2), 75-91.

23. Gallego, I., \& Rodriguez, L. (2005). Situation of Intangible Assets in Spanish Firms: an Empirical Analysis. Journal of Intellectual Capital, 6(1), 105-126.

24. Hamdam, H., \& Damirchi, G. V. (2011). Managing Intellectual Capital of Small and Medium Size Enterprises in Iran Case Study: Ardabil Province SMEs. 3, 2, 163-167.

25. Hofstede, G. (1984). Cultural dimensions in management and planning. Asia Pacific journal of management, 1(2), 81-99.

26. Hsu, L. C., \& Wang, C.-H. (2012). Clarifying the Effect of Intellectual Capital on Performance: The Mediating Role of Dynamic Capability. British Journal of Management, 23(2), 179.

27. Huang, C. L., \& Kung, F. H. (2011). Environmental consciousness and intellectual capital management Evidence from Taiwan's manufacturing industry. [Article]. Management Decision, 49(9-10), 1405-1425.

28. Huggins, R., \& Weir, M. (2007a). Intellectual assets and public policy. Journal of Intellectual Capital, 8(4), 708-720.

29. Huggins, R., \& Weir, M. (2007b). Managing Intellectual Assets in SMEs: Evaluating the Scope for Policy Intervention. Int. J. Learning and Intellectual Capital, 4(4), 412-429.

30. INEGI. (2009). Micro, pequena, mediana y gran empresa. Estratificacion de los establecimientos. Aguascalientes: Instituto Nacional de Estadistica y Geografia.

31. Inmyxai, S., \& Takahashi, Y. (2009). Firm resources and business performance in the Lao PDR: Implications for SMEs in the LDC context. Journal of Indian Business Research, 1(2/3), 163-187.

32. Jardón, C. M., \& Martos, M. S. (2009). Intellectual capital and performance in wood industries of Argentina. Journal of Intellectual Capital, 10(4), 600-616.

33. Kamukama, N., Ahiauzu, A., \& Ntayi, J. (2010). Intellectual Capital and Performance: Testing Interaction Effects. Journal of Intellectual Capital, 11(4), 554-574.

34. Kamukama, N., Ahiauzu, A., \& Ntayi, J. (2011). Competitive Advantage: Mediator of Intellectual Capital and Performance. Journal of Intellectual Capital, 12(1), 152-164.

35. Kaufmann, L., \& Schneider, Y. (2004). Intangibles: A synthesis of current research. Journal of Intellectual Capital, 5(3), 366-388.

36. Khalique, M. (2011). Do Malaysia and Pakistan are Suitable for a Comparative Study of SMEs: An Intellectual Capital Perspective? Interdisciplinary Journal of Contemporary Research in Business, 3(8), 98107.

37. Kiong T., I. W., \& Hooi H., L. (2009). Intellectual Capital Performance of Financial Institutions in Malaysia. Journal of Intellectual Capital, 10(4), 588-599.

38. Kvale, S. (1996). Inerviews: An Introduction to Qualitative Research Interviewing. Michigan: Sage Publications.

39. Lopez-Acevedo, G., \& Tinajero-Bravo, M. (2010). Evaluating Enterprise Support Programs Using Panel Firm Data. In W. Bank (Ed.), Evalating Small and Medium Enterprise Support Programs in Latin America: The World Bank.

40. Lopez, V. A. (2006). An Alternative Methodology for Testing a Resource-Based View Linking Intangible Resources and Long-Term Performance. Irish Journal of Management, 27(2), 49-66.

41. Mahoney, J. (2005). Resource-based theory, dynamic capabilities, and real options Economic foundations of strategy. Thousand Oaks: Sage Publications.

42. Maxwell, J. (2005). Qualitative Research Design. An Interactive Approach (Vol. 41). Thousand Oaks, California: Sage.

43. McKelvie, A., \& Davidsson, P. (2009). From Resource Base to Dynamic Capabilities: an Investigation of New Firms. British Journal of Management, 20, 63-80.

44. Ngah, R. (2009). Relationship of Intellectual Capital, Innovation and Organizational Performance: a Preliminary Study in Malaysian SMEs. International Journal of Management Innovation Systems, 1(1), 113.

45. OECD. (2004). Chapitre 1: Caractéristiques et Importance des PME. Revue de l'OCDE sur le Développement, 2, 37-46.

46. OECD. (2010). SMEs Entrepreneurship and Innovation OECD Studies on SMEs and Entrepreneurship. Paris: OECD. 
47. Pal, K., \& Soriya, S. (2012). IC performance of Indian pharmaceutical and textile industry. Journal of Intellectual Capital, 13(1), 120-137. doi: http://dx.doi.org/10.1108/14691931211196240.

48. Palys, T., \& Atchison, C. (2008). Research Decisions: Qualitative and Quantitatives Perspectives (4th ed.). Toronto: Thomson Nelson.

49. Phusavat, K., Comepa, N., Sitko-Lutek, A., \& Ooi, K. B. (2011). Interrelationships Between Intellectual Capital and Performance: Empirical Examination. Industrial Management \& Data Systems, 111(6), 810829.

50. Pike, S., boldt-Christmas, L., \& Roos, G. (2006). Intellectual Capital: Origin and Evolution. Int. J. Learning and Intellectual Capital, 3(3), 233-248.

51. Piperopoulos, P. (2010). Tacit knowledge and emotional intelligence: the 'intangible' values of SMEs. Strategic Change, 19(3-4), 125-139.

52. Porter, M. E. (2008). Competitive advantage: Creating and sustaining superior performance: Free press.

53. Rangone, A. (1999). A Resource-Based Approach to Strategy Analysis in Small-Medium Sized Enterprises Small Business Economics, 12, 233-248.

54. Rodriguez A., J. M., Rubio A., L., \& Esteban A., C. (2005). Proposal of an Intellectual Capital Model for the Spanish Hospitality Sector. Int. J. Learning and Intellectual Capital, 2(3), 305-320.

55. Ruiz, A. F. (2001). La Innovacion en las PYMES. Innovacion y creatividad.

56. Stam, C. D. (2005). Intellectual Productivity: Measuring and Improving Productivity in the Intangible Economy. Int. J. Learning and Intellectual Capital, 2(2), 128-146.

57. Steenkamp, N., \& Kashyap, V. (2010). Importance and contribution of intangible assets: SME managers' perceptions. Journal of Intellectual Capital, 11(3), 368-390. doi: http://dx.doi.org/10.1108/14691931011064590.

58. Teece, D. (2007). Explicating dynamic capabilities: The nature of microfoundations of enterprise performance. Strategic Management Journal, 28(13), 1319-1350.

59. Teece, D., \& Pisano, G. (1994). The dynamic capabilities of firms: an introduction. Industrial and Corporate Change, 3(3), 537-556.

60. Teece, D., Pisano, G., \& Shuen, A. (1997). Dynamic capabilities and strategic management. Strategic Management Journal, 18(7), 509-533.

61. The World Bank. (2007). Evaluating Mexico's Small and Medium Enterprise Programs. Washington: The World Bank.

62. Truijens, O. (2003). A critical review of the Resource-based view of the firm. Paper presented at the Sprouts: Working Papers on Information Systems.

63. Wang, C. L., \& Ahmed, P. K. (2007). Dynamic capabilities: A review and research agenda. International Journal of Management Reviews, 9(1), 31-51. doi: 10.1111/j.1468-2370.2007.00201.x.

64. Yi, A., \& Davey, H. (2010). Intellectual Capital Disclosure in Chinese (mainland) Companies. Journal of Intellectual Capital, 11(3), 326-347.

65. Zaidi, A., \& Siti Norezam, O. (2011). Understanding dynamic capability as an ongoing concept for studying technological capability. International Journal of Business and Social Science, 2(6), 224-234. 